\title{
Comparison of Sonication with Maceration on Antioxidant Potency of Anthocyanin and Karotenoid of Tamarillo (Solanum betaceaum Cav.)
}

\author{
Gusti Ayu Kadek Diah Puspawati*, Yustinus Marsono², Supriyadi2, Ria Armunanto \\ ${ }^{1}$ Study Program on Food Science and Technology, Faculty of Agricultural Technology, Udayana University, Jl. Kampus \\ Bukit Jimbaran, Badung, Bali 80225, Indonesia \\ ${ }^{2}$ Food Science Study Program, Faculty of Agricultural Technology, Universitas Gadjah Mada, Jl. Flora No. 1, \\ Bulaksumur, Yogyakarta 55281, Indonesia \\ 3Department of Chemistry, Faculty of Mathematics and Natural Sciences, Universitas Gadjah \\ Mada, Jl. Sekip, Yogyakarta 55281, Indonesia \\ *Email: diahpuspawati@unud.ac.id
}

Submission: 2 Januari 2018; Acceptance: 22 Agustus 2018

\begin{abstract}
Tamarillo is an underutilized fruit in Indonesia, despite the fact that it contains two pigments (anthocyanin and carotenoid) with different properties (polar and non polar). Besides, there is a scarce information about extraction of anthocyanin and carotenoid of Tamarillo using sonication extraction. This study was aimed to investigate the comparison of extraction methods of sonication with maceration on antioxidant potency of anthocyanin and carotenoid of Tamarillo. Two pigmen types (anthocyanin and carotenoid) were extracted using two different methods (sonication and maceration). The parameters of analysis were yield, antioxidant activity (DPPH) with IC $_{50}$ Ferric Reducing Antioxidant Power (FRAP), anthocyanin total, carotenoid total, phenolic total and scanning electron microscope of cover cell of material. The antioxidant potencies for both anthocyanin and carotenoid by sonication method were higher than those of obtained by maceration method. The results showed that both sonication and maceration were suitable for extraction of anthocyanin and carotenoid from Tamarillo.
\end{abstract}

Keywords: antioxidant; anthocyanin; carotenoid; sonication; tamarillo

\section{INTRODUCTION}

Tamarillo (Solanum betaceaum Cav) known as tomato tree or terong Belanda, is one of the fruit vegetables that is not yet widely used as food in Indonesia compared with tomatoes or purple eggplants. On the other hand, Tamarillo is an export commodity several countries such as New Zealand, America and Brazil. The breed commonly found in Indonesia is the red one. The red breed has red peel, orange flesh, dark red placenta and hard brownish black seeds (De Rosso and Mercadante, 2007).

According to Osorio et al. (2012), red Tamarillo contains both anthocyanin and carotenoid bioactive components, and they have differing characteristics, namely polar and bipolar. Both compounds are natural antioxidants. In Indonesia the availability of fruits which contain the two components at the same time is still limited.

Anthocyanin belongs to phenolic compound, in the flavonoid group, which has healthy properties, such as lowering blood sugar for type 2 diabete (Sancho and Pastore, 2012). Carotenoid is a non-polar C40 tetraterpenoid compound which has a polydiene structure and health properties as anti-diabetes (Sugiura et al., 2015).

Anthocyanin and carotenoid's potentials as antidiabetes for type 2 can be caused by antioxidant properties, because in type 2 diabetes an oxidative stress occurs, and oxidative stress can be suppressed by antioxidant. Antioxidant components of a substance (tamarillo) can be taken through extraction process. Tamarillo's anthocyanin and carotenoid compound extraction and identification has been reported by 
De Rosso \& Mercadante (2007), who stated that anthocyanin and carotenoid compound extraction from the whole tamarillo fruit takes $12 \mathrm{~h}$. Mandal and Ghosal (2012), reported that extraction from several parts of tamarillo fruit could be conducted at a temperature of $50{ }^{\circ} \mathrm{C}$ for 8 hours. Tamarillo extraction that has been performed used maceration and soxhlet methods.

Maceration and soxhlet methods are conventional methods which are simple and easy to perform, but it takes a considerable amount of time, between 1 to $24 \mathrm{~h}$, and in soxhlet method, high temperature $\left(50^{\circ}\right)$ is required. Temperature increase during extraction $\left(>50^{\circ}\right)$ can cause damage to anthocyanin (Pingret et al., 2013).

The sonication method, which is considered as a green extraction method, was first developed to overcome the drawbacks of conventional methods, such as maceration. The sonication method can be performed in much shorter time, less than $1 \mathrm{~h}$, and the damage effects during the process is low or can be minimized (Chemat et al., 2016). Ma et al. (2009) reported that degradation of antioxidant compounds as the effect of sonication temperature can be minimized, if the temperature reaches $<40^{\circ} \mathrm{C}$, it can be controlled by applying ice cubes.

The sonication method principle involves ultrasonic wave which creates cavitation. The cavitation phenomenon creates energy, temperature increase and local pressure. This also generates a micro jet, material surface damage towards the inner part, which creates a rapid mass transfer, faster extraction time and more rendemen produced (Medina-Torres et al., 2017).

Sonication extraction of tamarillo has been reported by Asmara et al. (2013), but on tamarillo peel using ultrasonic wave at $60^{\circ} \mathrm{C}$ temperature in 30 minutes. The research used a high temperature above $40{ }^{\circ} \mathrm{C}$, and involved materials not to be eaten. The sonication method for tamarillo anthocyanin and carotenoid extraction involving the edible part of the fruit and using room temperature $\left(\leq 30^{\circ} \mathrm{C}\right)$ has not been reported. In sonication, high temperature increase can cause damage on the compound which has antioxidant characteristics. Therefore, this research aims to evaluate rendemen and antioxidant potentials of anthocyanin and carotenoid of tamarillo extract using a sonication method compared with control maceration method.

\section{RESEARCH METHOD}

\section{Materials}

Red variety of Tamarillo, at age of 6 months after producing flowers, taken from Dieng plateau,

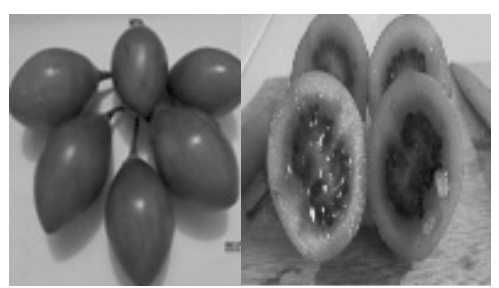

Figure 1. Tamarillo fruit and its cross sections

Wonosobo, Central Java, Indonesia. The form of and the cross section of the tamarillo fruit is shown in Figure 1. Ethanol solvent $70 \%$ (technical); acetone (technical) and citric acid (Gajah, technical) obtained from Brataco, Jakarta, Indonesia. Pro analysis chemical substances: Folin Ciocalteau's phenol reagent, $\mathrm{FeCl}_{3} .7 \mathrm{H}_{2} \mathrm{O}$, $\mathrm{FeSO}_{4} \cdot 6 \mathrm{H}_{2} \mathrm{O}$ and $\mathrm{Na}_{2} \mathrm{CO}_{3}$, obtained from Merck, Darmstadt, Germany. Pro analysis chemical substances: ethanol, metanol, acetone, 2,3,5-triphenyl-1,3,4-triaze2-azoniacyclopenta-1,4-diene chloride (TPTZ) dan 2,2-diphenyl-1-picrylhydrazyl (DPPH), obtained from Sigma Aldrich, St. Louis, MO, USA.

\section{Equipments}

The equipments used for extraction included sonicators (Elma T760DH, Singen, Germany), rotary evaporator (IKA WERKE RV06-ML, Staufen, Germany) and shaking water bath (Juloba SW22, Seelbach, Germany). The equipments for analysis were UV-Vis spectrophotometer (Genesys S10, Germany) and Pyrex glass wares (Iwaki, Tokyo, Japan). The tool used for cell surface morphology analysis was a scanning electron microscope (JOEL JSM-6510, Tokyo, Japan)

\section{Tamarillo Anthocyanin Extraction using the maceration method}

Tamarillo anthocyanin extraction using the maceration method refers to Atiqah et al. (2014). As much as $300 \mathrm{~g}$ of tamarillo fruits were peeled, and then they are blended without adding water for 2 minutes, resulting in fruit puree. As much as $200 \mathrm{~g}$ of puree was put into a tinted bottle, added with $800 \mathrm{ml}$ ethanol solvent $70 \%$ (technical), containing $3 \%$ citric acid, and then mixed using a magnetic stirrer for 2 minutes. The mixture was then subjected to maceration extraction in a shaking water bath with a $50 \mathrm{rpm}$ shaking speed, $30{ }^{\circ} \mathrm{C}$ temperature for 20 minutes. Filtrate from the extraction was evaporated to rid of its solvent using a rotary evaporator at a heating bath temperature of $35^{\circ} \mathrm{C}$ and a $176 \mathrm{mbar}$ initial vacuum pressure, which was gradually lowered to reach 72 mbar, resulting in a thick extract. The extract was a raw tamarillo anthocyanin extract, this was stored in a tinted glass bottle, kept at $-20{ }^{\circ} \mathrm{C}$ until the time for analysis. 


\section{Tamarillo Anthocyanin Extraction using Sonication Method}

Tamarillo anthocyanin extraction using sonication method refers to Celli et al. (2015). The procedures before and after the extraction process were the same with tamarillo anthocyanin extraction using maceration method. Sonication extraction method was performed in a sonicator at a $40 \mathrm{kHz}$ frequency, $100 \%$ power, initial temperature of $27^{\circ} \mathrm{C}$ and end temperature of $29^{\circ} \mathrm{C}$ for 20 minutes.

\section{Tamarillo Carotenoid Extraction using Maceration Method}

Tamarillo anthocyanin extraction was conducted using sonication method refers to De Rosso and Mercadante (2007). As much as $350 \mathrm{~kg}$ of tamarillo fruit was taken by removing the peel, and then blended without adding water for 5 minutes to get a fruit puree. the puree is then placed in tinted glass bottle, added with $800 \mathrm{~mL}$ of acetone solvent $80 \%$ (technical), and then mixed using a magnetic stirrer for 5 minutes. The mixture was then extracted using maceration in a shaking water bath at $50 \mathrm{rpm}$ shaking speed and $30^{\circ} \mathrm{C}$ temperature for 30 minutes. The filtrate was then retrieved, and then passed through a separator funnel filled with petroleum ether. The next step was fetching the yellow-orange colored solution. The solution was then put into a rotary evaporator at a $30{ }^{\circ} \mathrm{C}$ heating bath temperature to evaporate its solvent, applying a 356 mbar initial pressure and 72 mbar end pressure until a rather thick extract was obtained. The extract was called tamarillo raw carotenoid extract.

\section{Tamarillo Carotenoid Extraction using Sonication Method}

Tamarillo carotenoid extraction using sonication method refers to Santos et al. (2015). The procedures before and after the extraction process were similar with anthocyanin extraction using maceration method. Extraction was conducted in a sonicator under conditions similar with anthocyanin extraction, only the time of extraction is 30 minutes.

\section{Determining Rendemen}

Determining rendemen refers to Annegowda et al. (2012). Rendemen was determined by weighing the

$$
\text { Rendemen }(\%)=\left(\frac{\mathrm{Ba}-\mathrm{Be}}{\mathrm{Be}}\right) \times 100 \%
$$

Remarks :

$\mathrm{Ba}$ (fruit puree weight; Be (extract weight after the solvent is evaporated) tamarillo fruit puree and its raw extract weight after the solvent was evaporated. The rendemen calculation was determined using equation 1 :

\section{Analysis of Antioxidant Activity as Radical Scavenging Antioxidants (RSA) and $\mathrm{IC}_{\mathbf{5 0}}$}

Analysis of RSA using DPPH refers to Aadil et al. (2014). $600 \mu \mathrm{L}$ of sample solution $(100 \mu \mathrm{g} / \mathrm{mL})$ was added with $1400 \mu \mathrm{L}$ of DPPH solution $(0,01 \mathrm{M})$. The mixture was incubated in a dark condition, room temperature, for 30 minutes, and then the absorbance in read using a spectrophotometer at $\lambda 517 \mathrm{~nm}$. A blank was made by changing the sample solution with a solvent. The percentage of RSA is determined with Equation 2.

$$
\% \mathrm{RSA}=\left(\frac{\mathrm{Ab}-\mathrm{As}}{\mathrm{Ab}}\right) \times 100 \%
$$

Remarks :

Ab (blank absorbance); As (sample absorbance)

$\mathrm{IC}_{50}$ was performed by making several extract concentrations $(20,40,60,80,100 \mu \mathrm{g} / \mathrm{mL})$ and by making a linear equation, in which the $x$ axis $=$ extract concentration and the $y$ axis $=$ percentage of inhibition. $\mathrm{IC}_{50}$ is determined using Equation 3.

$$
\mathrm{IC}_{50}=\frac{50-\mathrm{a}}{\mathrm{b}}
$$

\section{Analysis of Antioxidant Activity as Ferric Reducing Antioxidant Power (FRAP)}

Analysis of FRAP refers to Benzie \& Strain (1996). $100 \mu \mathrm{L}$ of sample solution $(100 \mu \mathrm{g} / \mathrm{mL})$ added with 1200 $\mu L$ FRAP solution (acetate buffer: TPTZ: $\mathrm{FeCl}_{3} \cdot 6 \mathrm{H}_{2} \mathrm{O}$; ratio 10:1:1), mixed using a vortex. The mixture was then incubated at $37^{\circ} \mathrm{C}$ for 4 minutes, absorbance was read at a spectrophotometer $\lambda 593 \mathrm{~nm}$. Standard solution of $\mathrm{FeSO} 4.6 \mathrm{H} 2 \mathrm{O}$ was made with several concentrations (10, $20,30,40$ and $50 \mathrm{mM}$ ), and antioxidant activity as $\mathrm{Fe}^{3+}$ ion reducer to $\mathrm{Fe}^{2+}$ was determined using a standard curve linear equation.

\section{Analysis of Total Anthocyanin}

Analysis of total anthocyanin refers to Giusti \& Wrolstad (2001). Sample solution $(1000 \mu \mathrm{g} / \mathrm{mL})$ is poured with $500 \mu \mathrm{L}$ each into two reaction tubes, the first one =was added with $2.5 \mathrm{~mL} \mathrm{KCl} \mathrm{pH} 1$ buffer, and the second one was added with $\mathrm{pH} 4.5$ acetate buffer. The mixed solutions were incubated in a dark room for 30 minutes, absorbance was read using spectrophotometer at $\lambda 520 \mathrm{~nm}$ and $\lambda 700 \mathrm{~nm}$. Anthocyanin extract content 
calculation as delphinidin 3 rutinoside was determined using Equations 4 and 5.

$$
\begin{aligned}
& A=(A 520-A 700) p H 1-(A 520-A 700) p H 4,5 \\
& T A=\left(\frac{m g}{k g}\right)=\frac{A \times B M \times D F \times V \times 1000}{L \times \varepsilon \times m}
\end{aligned}
$$

Remarks: TA (total anthocyanin); BM (molecule weight of delphinidine 3-rutinoside $(611 \mathrm{~mol} / \mathrm{g})$; DF (dilution factor); V (total volume (L); L (length $(1 \mathrm{~cm}) ; \varepsilon$ (extension coefficient ( $\mathrm{mol} / \mathrm{L}$ $\times \mathrm{cm}$ ); $\mathrm{m}$ (extract weight $(\mathrm{kg}) ; 1000$ (conversion from $\mathrm{g}$ to $\mathrm{mg}$ )

\section{Analysis of Total Carotenoid}

Total carotenoid was assessed based on Kurniawan et al. (2010). As much as $2 \mathrm{~mL}$ of raw carotenoid extract, added with $10 \mathrm{~mL}$ acetone solvent $80 \%$ pa, and then homogenized using vortex for 5 minutes. The solution was diluted 10 times, and then read for its absorbance using $\lambda 480 \mathrm{~nm}, \lambda 645 \mathrm{~nm}$ and $\lambda 663 \mathrm{~nm}$ spectrophotometer. Total carotenoid was determined using equation 6 :

$$
T K\left(\frac{\mu m o l}{L}\right)=\left((A 480+(0,114 \times A 663))-\frac{0,638 \times A 645 \times V \times F P \times 1000}{112,5 \times W}\right)
$$

Remarks:

$1 \mu \mathrm{mol} / \mathrm{L}$ ( $27,25 \mathrm{mg} / \mathrm{L}$ (Hendry dan Grime 1993); A480 (absorbance at $480 \mathrm{~nm}$ wavelength); A663 (absorbance at 663 $\mathrm{nm}$ wavelength); A645 (absorbance at $645 \mathrm{~nm}$ wavelength); V (extract volume $(\mathrm{mL})$; FP (dilution factor); W (sample weight $(\mathrm{g})$.

\section{Analysis of Total Phenolic}

Total phenolic was determined using folin ciocalteu and gallic acid standard refers to Rocha et al. (2017). 200 $\mu \mathrm{L}$ sample solution $(1000 \mu \mathrm{g} / \mathrm{mL})$, is added with 1000 $\mu \mathrm{L}$ folin ciocalteau (10\%). The mixture was incubated for 5 minutes, and then added with 800 uL $\mathrm{Na} 2 \mathrm{CO} 3$ $(7,5 \%)$, incubated again for 30 minutes. The mixture was then read for absorbance at $\lambda 763 \mathrm{~nm}$. Gallic acid standard solutions were made at several concentrations $(100,200,300,400$ and $500 \mu \mathrm{g} / \mathrm{mL})$. The total phenolic in the extract was determined using Equation 7.

$$
T P(\%)=\frac{a \times F P \times T V \times 100}{\text { sample weight }(g)}
$$

Remarks:

a ( $x$ value of gallic acid standard linear equation); FP (dilution factor); TV (total volume).

\section{Material Cell Surface Morphology by means of Scanning Eelectron Microscope (SEM)}

Cell surface morphology was performed on the fruit puree and extraction residue, which had been made into dry powder refers to Altemimi et al. (2016).
Tamarillo fruit puree as the basic ingredient for tamarillo anthocyanin and carotenoid extraction and residue of extraction from the maceration and sonication methods are dried using freeze drying, and then refined to become dry powder. The next step, $0.5 \mathrm{~g}$ of sample powder was sprinkled evenly on the sample container. Subsequently, it was coated by putting in the chamber for 20 minutes. The sample was observed for its cell surface morphology, with a 5,000 magnification.

\section{Data Analysis}

Data analysis was performed using an independent t-test with SPSS 20.0 for Windows. The confidence level was $5 \%(p<0.05)$.

\section{RESULTS AND DISCUSSIONS}

\section{Tamarillo Raw Anthocyanin Extract (TACE) and Tamarillo Raw Carotenoid Extract (TCCE) by Maceration and Sonication}

Rendemen of tamarillo raw anthocyanin extract (EKAT) and tamarillo raw carotenoid extract (EKKT) using sonication method is higher than maceration method ( $p<0.05)$. Rendemen of EKAT and EKKT as the results of maceration and sonication were shown in Figure 2.

Rendemen of TACE as the results of maceration and sonication processes were $21.45 \pm 1.25 \%$ and $24.70 \pm 1.42 \%$ consecutively, the sonication result is $15.14 \%$ higher. The results for TACE were 12.37 $\pm 0,42 \%$ and $15.10 \pm 0,27 \%$ consecutively, the sonication result was $22.13 \%$ higher. This indicates that tamarillo anthocyanin extraction using the sonication method at a frequency of $40 \mathrm{kHz}, 100 \%$ power, initial temperature $27^{\circ} \mathrm{C}$ and end temperature $29^{\circ} \mathrm{C}$, for 20 minutes and tamarillo carotenoid extraction using the sonication method at the same condition, but for 30

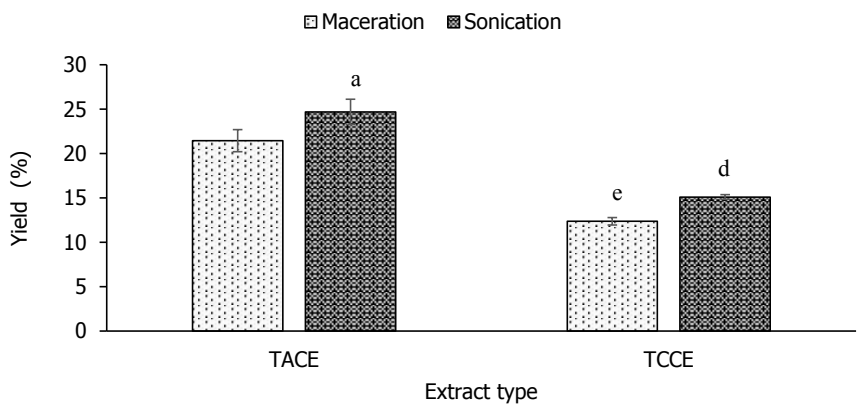

Figure 2. Rendemen of tamarillo raw anthocyanin extract (TACE) and tamarillo raw carotenoid extract (TCCE) using maceration and sonication methods

Note: TACE = Tamariilo athocyanin crude extract; TCCE = Tamarillo carotenoid crude extract 
minutes, will produce higher rendemen than using the maceration method.

The higher TACE and TCCE rendemen from sonication than from maceration is probably caused by the ultrasonic wave which creates a cavitation phenomenon. The cavitation phenomenon can accelerate molecule movement, accelerate solvent penetration into the material, which causes more compounds to be extracted. Medina-torres et al. (2017) confirmed that ultrasonic wave which creates the cavitation phenomenon causes energy formation, temperature and local pressure increase which create a micro jet. The condition will accelerate mass transfer process. The results of sonication that was higher than maceration is confirmed by a report from Rombaut et al. (2014). It was reported that a temperature increased below $60^{\circ} \mathrm{C}$ caused reduction of density and viscosity, increase solubility of the solute with solvents and reduction surface tension. These conditions helped solvents to enter into the material and accelerate mass transfer process. Another reason could be sonication method did not cause degradation of tamarillo anthocyanin and carotenoid. Ma et al. (2009), reported that antioxidant component damage can be suppressed if the temperature was below $40^{\circ} \mathrm{C}$ and was controlled using ice blocks.

The rendemen of TACE and TCCE from sonication which was higher than that of maceration is consistent with the previous research, Ivanovic et al. (2014), reported that sonication can increase rendemen better than maceration on dragon fruit flesh with $22.94 \%$ and blackberry fruit flesh between $5.2-6.3 \%$. The previous studies also reported that carotenoid extract rendemen from tomato lycopene using the sonication method is 26\% higher (He \& Teoh,2012).

\section{Radical Scavenging Antioxidant and IC $_{50}$ TACE and TCCE from Maceration and Sonication}

Radical scavenging antioxidant (RSA) with 2.2-diphenyl-1-picrylhidrazyl (DPPH) was stated as the

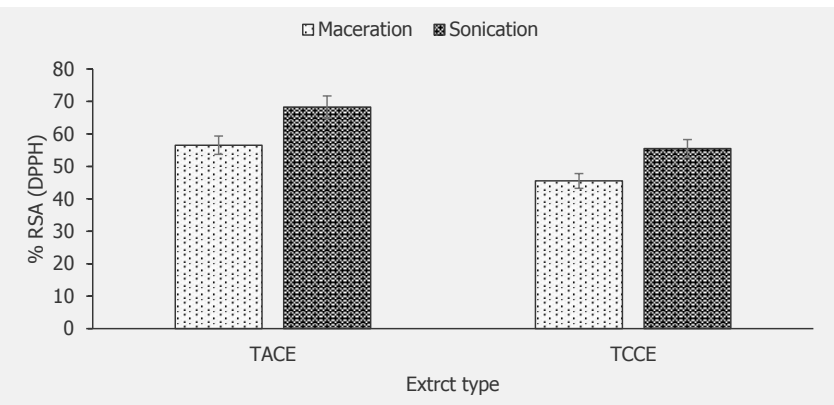

Figure 3. RSA percentage of tamarillo raw anthocyanin extract (TACE) and tamarillo raw carotenoid extract (TCCE) using maceration and sonication methods percentage of antioxidant activity in scavenging free radicals DPPH (\%RSA) and the inhibition concentration is in the form of $\mathrm{IC}_{50}$ value. The $\mathrm{IC}_{50}$ value here is the concentration of TACE and TCCE as scavenging DPPH free radicals by $50 \%$. The concentration of TACE and TCCE is used as the comparison indicator of antioxidant activity with other compounds. The RSA percentage of TACE and TCCE from sonication shows higher results than from maceration $(p<0.05)$ (Figure 3$)$.

RSA percentage of TACE from maceration and sonication were $56.52 \pm 1.27 \%$ and $68.28 \pm 3.28 \%$, in which the result from sonication was $20.81 \%$ higher. Whereas for TCCE, the RSA percentage using maceration and sonication are: $46.40 \pm 2.31 \%$ and $55.48 \pm 2.44 \%$. The result from sonication is $21.92 \%$ higher. This indicates that the sonication method of tamarillo anthocyanin and carotenoid extraction can produce higher RSA percentage than maceration. The RSA percentage of sonication method which is higher than maceration method was probably because of ultrasonic wave with cavitation phenomenon, this accelerates material surface damage so that mass transfer occured faster and the extraction process of antioxidant compounds that were complexly bound with other compounds will be extracted faster and in higher quantity. Anthocyanin compounds that were bound on the cell walls (cellulose and pectin) and protein create a complex compound on the vacuole and carotenoid compound is bound on the cell wall constituent component and fat forms a complex compound in the inner part of chromoplast membrane can be quickly degraded with the existence of cavitation phenomenon in sonication (Phan et al., 2015). The mechanism of antioxidant activity from the compound is through proton transfer $(\mathrm{H}+)$ which dampen free radical compounds (DPPH) into non radical (Molyneux, 2004).

The higher RSA percentage in TACE from sonication method was in line with a report from Aadil et al. (2014), which stated that sonication in anthocyanin extraction from grapes, in 30 minutes can increase RSA percentage up to $16.67 \%$ than maceration method. Whereas the higher result of carotenoid extraction using sonication method compared to using maceration method is similar with the report from Saikia et al. (2015), which stated that pineapple carotenoid extraction using sonication for 30 increased antioxidant (DPPH) activity by $40.55 \%$ compared to maceration.

Concentration of RSA inhibition percentage at $50 \%$ or $\mathrm{IC}_{50}$ value of TACE and TCCE shows lower sonication result compared to maceration result $(p<0.05)$ (data not shown in Figure). The results show lower $\mathrm{IC}_{50}$ therefore, the RSA percentage was higher. $\mathrm{IC}_{50}$ values of TACE using maceration and sonication were 95.50 
$\mu \mathrm{g} / \mathrm{mL}$ and $85.32 \mu \mathrm{g} / \mathrm{mL}$, whereas IC $_{50}$ values of TCCE using maceration and sonication were $99.94 \mu \mathrm{g} / \mathrm{mL}$ and $87.71 \mu \mathrm{g} / \mathrm{mL}$

$\mathrm{IC}_{50}$ values of TACE and TCCE using sonication was lower than using maceration because of cavitation phenomenon which accelerates mass transfer, and therefore it can extract compounds that have antioxidant activity faster and in bigger quantity, which caused lower $\mathrm{IC}_{50}$ value. The $\mathrm{IC}_{50}$ value of TACE and TCCE was below $100 \mu \mathrm{g} / \mathrm{mL}$, therefore, TACE and TCCE belong to strong antioxidants (Molyneux, 2004). The $\mathrm{IC}_{50}$ value of TACE and TCCE of Tamarillo obtained in this study were higher than vitamin $\mathrm{C}(29.83 \mu \mathrm{g} / \mathrm{mL})$ and Trolox $(30.53 \mu \mathrm{g} / \mathrm{mL})$ and lower blackberry extract $(96 \pm 0,32$ $\mu \mathrm{g} / \mathrm{mL}$ )(Ivanovic et al., 2014). This indicates that TACE and TCCE have antioxidant activity for scavenging free radicals, lower than vitamin $\mathrm{C}$ and Trolox, but higher than blackberry extract.

\section{Ferric Reducing Antioxidant Power (FRAP) of TACE and TCCE Using Maceration and Sonication}

Antioxidant activity (FRAP) of TACE and TCCE using sonication is higher than maceration $(p<0,05)$. Antioxidant activity (FRAP) of TACE and TCCE using maceration and sonication is shown in Figure 4.

Antioxidant activities (FRAP) of TACE using maceration and sonication were $570.93 \pm 5.62 \mathrm{mM}$ $\mathrm{FeSO}_{4} \cdot 6 \mathrm{H}_{2} \mathrm{O} / 100 \mathrm{~g}$ extract and $694.45 \pm 25.56 \mathrm{mM}$ $\mathrm{FeSO}_{4} \cdot 6 \mathrm{H}_{2} \mathrm{O} / 100 \mathrm{~g}$ extract. The result from sonication was $17.79 \%$ higher. The activities for TCCE were 278.46 $\pm 14.77 \mathrm{mM} \mathrm{FeSO} \mathrm{H}_{4} \cdot 6 \mathrm{H}_{2} \mathrm{O} / 100 \mathrm{~g}$ extract and $332.95 \pm$ $19.41 \mathrm{mM} \mathrm{FeSO}_{4} \cdot 6 \mathrm{H}_{2} \mathrm{O} / 100 \mathrm{~g}$ extrac, in which the result from sonication was $16.37 \%$ higher. This indicated that sonication result with its cavitation phenomenon can increase TACE and TCCE potentials as antioxidants in reducing ferric ion $\left(\mathrm{Fe}^{+3}\right)$ into ferrous ion $\left(\mathrm{Fe}^{+2}\right)$.

This is shown by the formation of blue color that gets darker (Benzie and Strain, 1996). The ability to reduce $\mathrm{Fe}^{3+}$ into $\mathrm{Fe}^{2+}$ from tamarillo anthocyanin and

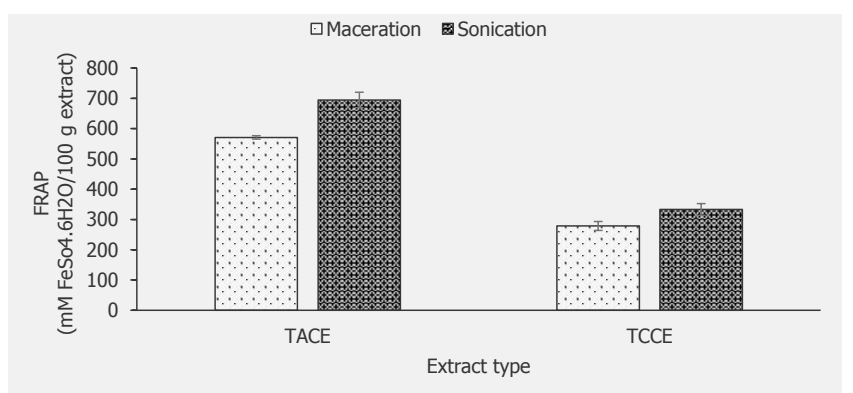

Figure 4. Antioxidant activity (FRAP) of tamarillo raw anthocyanin extract (TACE) and tamarillo raw carotenoid extract (TCCE) using maceration and sonication methods carotenoid is probably caused by the presence of electron as reducer, or the compound's ability as antioxidant. The antioxidant's property as reducer is due to the presence of hydroxyl cluster in the B ring of anthocyanin, whereas on carotenoid, it is due to the presence of conjugated dienes. The mechanism as antioxidant belongs to SET (single electron transfer) mechanism (Liang and Kitts, 2014).

The result of this study was supported Ramli et al. (2014), who reported that red dragon fruit extraction as antioxidant source has higher antioxidant activity (FRAP) using sonication compared with conventional extraction with antioxidant activity of $620 \mathrm{mM} \mathrm{FeSO} \cdot 6 \mathrm{H}_{2} \mathrm{O} / 100 \mathrm{~g}$ extract dan $609 \mathrm{mM} \mathrm{FeSO}_{4} \cdot 6 \mathrm{H}_{2} \mathrm{O} / 100 \mathrm{~g}$ extract.

\section{Total TACE Anthocyanin And Total TCCE Carotenoid from Maceration And Sonication}

Total anthocyanin in TACE was equivalent with monomeric anthocyanin delphinidine-3 rutinoside (De Rosso \& Mercadante, 2007). Total anthocyanin of TACE and total carotenoid in TCCE using sonication was higher than using maceration $(p<0.05)$ as presented in Figure 5.

Total anthocyanin in TACE using maceration and sonication was $286.77 \pm 21.96 \mathrm{mg} / 100 \mathrm{~g}$ extract and $386.48 \pm 19.82 \mathrm{mg} / 100 \mathrm{~g}$ extract, respectively indicating that sonication shows $34.77 \%$ higher value. Total carotenoids in TCCE using maceration and sonication were $29.93 \pm 1.18 \mathrm{mg} / 100 \mathrm{~g}$ extract and $50.80 \pm 3.02$ $\mathrm{mg} / 100 \mathrm{~g}$ extract, in which sonication shows $64.74 \%$ higher. This condition is probably caused by the fact that in sonication there is cavitation phenomenon which can increase anthocyanin or carotenoid mass transfer to the solvent, therefore, anthocyanin and carotenoid compounds extracted increases. In addition, low temperature of sonification did not cause carotenoid damage. According to Ma et al. (2009), the sonication temperature at $40 \square$ will cause damage to the bioactive components such as anthocyanin or carotenoid.

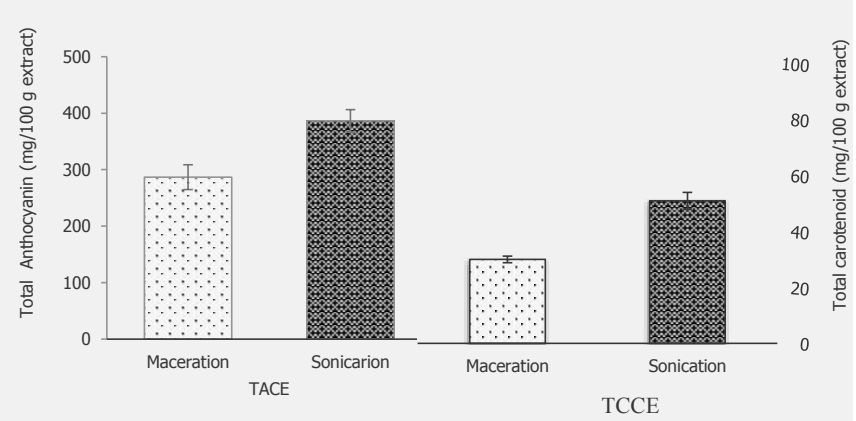

Figure 5. Total of tamarillo raw anthocyanin extract (TACE) and tamarillo raw carotenoid extract (TCCE) using maceration and sonication methods 
Total anthocyanin of $386,48 \mathrm{mg} / 100 \mathrm{~g}$ was higher than the total anthocyanin of tamarillo peels using sonication at a temperature of $60 \square$ for 30 minutes, which is $23.78 \mathrm{mg} / 100 \mathrm{~g}$ (Asmara et al., 2013). This difference is caused by the difference of tamarillo parts being used, temperature and duration of sonication extraction. The sonication method that can produce higher amount of anthocyanin and carotenoid is supported by a research on blueberry fruit anthocyanin extraction using sonication, which can increase the total anthocyanin of $58.33 \%$ (Rocha et al., 2017). Sonication results can increase the total carotenoid in carrot juice of 3.15\% (Jabbar et al., 2014).

\section{Total Phenolic in TACE and TCCE Using Maceration and Sonication}

Total phenolic in TACE and TCCE shows that using sonication is higher than using maceration $(p<0.05)$. Total phenolic in TACE and TCCE using maceration and sonication is presented in Figure 6. Total phenolics in TACE using maceration and sonication were $298.55 \pm$ $27.34 \mathrm{mg} \mathrm{GE} / 100 \mathrm{~g}$ extract and $395.64 \pm 38.93 \mathrm{mg}$ $\mathrm{GE} / 100 \mathrm{~g}$ extract. Using sonication produces $24.54 \%$ higher. Meanwhile the total phenolic in TCCE using maceration and sonication is as follows were 47.79 $\pm 4.53 \mathrm{mg} \mathrm{GE} / 100 \mathrm{~g}$ extract and $89.28 \pm 8.37 \mathrm{mg}$ $\mathrm{GE} / 100 \mathrm{~g}$ extract. Using sonication produces $46.48 \%$ higher. This was possible because sonication with its cavitation phenomenon can accelerate mass transfer, therefore, can extract more phenolic compound than using maceration. Total phenolic in TACE is higher than in TCCE, it is possibly because the total anthocyanin in TACE is higher than the total carotenoid in TCCE. Anthocyanin is a compound from the flavonoid group which belong to phenolic compounds, whereas carotenoid is from tetraterpenoid group, and does not

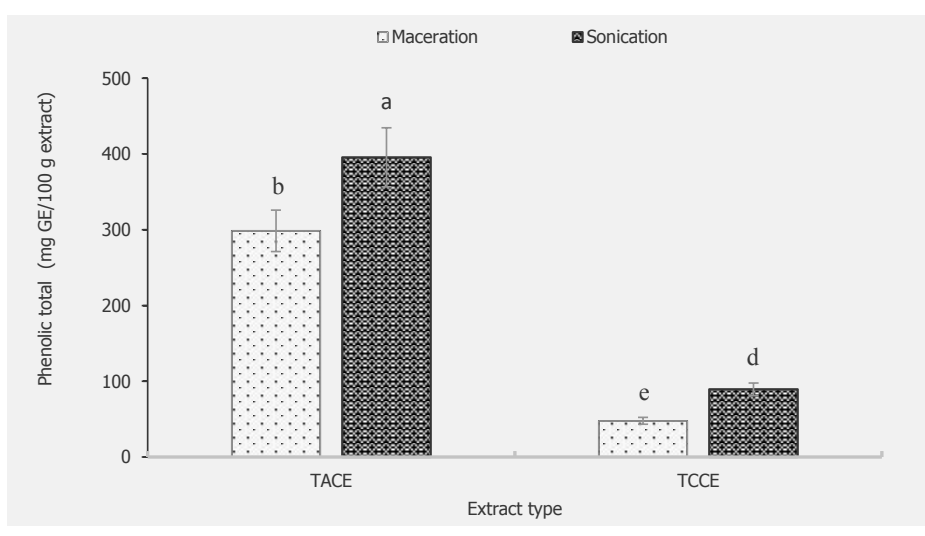

Figure 6. Total phenolic of tamarillo raw anthocyanin extract (TACE) and tamarillo raw carotenoid extract (TCCE) using maceration and sonication methods belong to phenolic compounds (Sancho and Pastore, 2012; Sugiura et al., 2015).

This result is consistent with what was reported by Rocha et al. (2017), that blueberry fruit extraction using sonication method shows $27.87 \%$ higher total phenolic than using maceration. In lemon fruit, extraction using sonication method shows 6.5 times higher increase of total phenolic compared to using maceration (Žlabur et al., 2016).

\section{Material Cell Surface Morphology and Residue of Tamarillo Anthocyanin and Carotenoid Extraction Using Maceration and Sonication}

Material cell surface morphology and residue of tamarillo anthocyanin and carotenoid extraction using maceration and sonication in the form of dry powder is performed using scanning electron microscope (SEM). The structure of material cell surface experience a change before and after extraction. There is also a difference between the results of extraction using maceration and using sonication. The differences happen both in anthocyanin extraction (Figures 7A-7C) and carotenoid extraction (Figures 7D-7F).

The material's cell surface before anthocyanin and carotenoid extraction showed no damage under 5,000 times magnification. The cell surface damage in maceration residue was less than that in sonication residue. In maceration, no sharp gap was found (black arrow mark), whereas in sonication it is quite the contrary, more intense and deep damage was found (black dotted arrow mark). This is probably because sonication, with its micro jet power, can induce deeper and more damage. This result is in line with what was
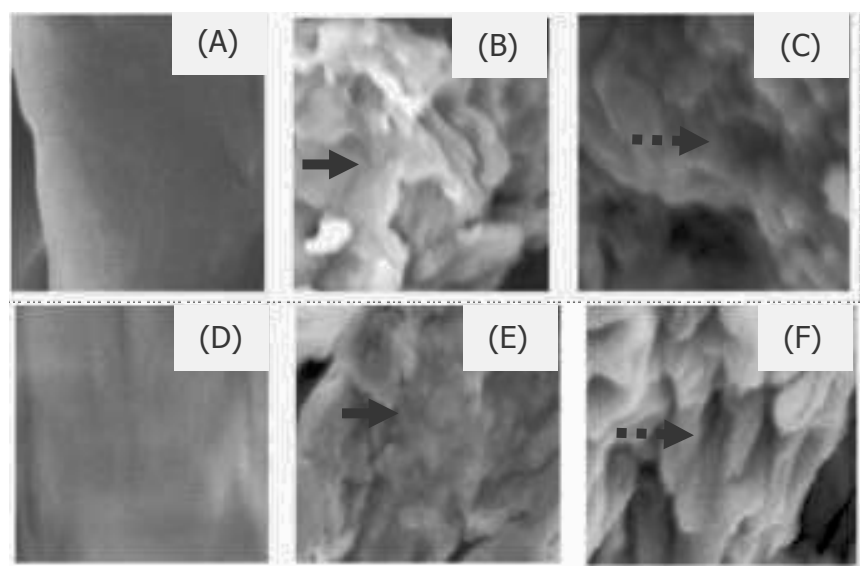

Figure 7. SEM results of material surface, 5,000 x magnification of (A) anthocyanin extraction material; (B) residue of anthocyanin extraction maceration; (C) residue of anthocyanin extraction sonication; (D) carotenoid extraction material; (E) residue of carotenoid extraction maceration; (F) residue of carotenoid extraction sonication 
reported by Altemimi et al. (2016), results of SEM on chayote after extraction using sonication showed more cell surface damage and more gaps towards the material's inner part than using maceration.

\section{CONCLUSION}

Sonication method was able to increase rendemen and TACE and TCCE antioxidant potentials than that maceration method. Rendemen increase of TACE and TCCE were $15.14 \%$ and $22.13 \%$, respectively. TACE and TCCE's antioxidant potentials using sonication method, including antioxidant activity (DPPH) and $\mathrm{IC}_{50}$ were as follows: $68.28 \pm 3.28 \% ; 55.48 \pm 2.44 \%$ and 85.32 $\mu \mathrm{g} / \mathrm{mL}$ : $87.71 \mu \mathrm{g} / \mathrm{mL}$; antioxidant activity (FRAP) of each: $694.45 \pm 25.56 \mathrm{mM}$ FeSO4.6H2O/ $100 \mathrm{~g}$ extract; $332.95 \pm 19.41 \mathrm{mM}$ FeSO4.6H2O/ $100 \mathrm{~g}$ extract; total anthocyanin of TACE: $386.48 \pm 19.28 \mathrm{mg} / 100 \mathrm{~g}$ extract; total carotenoid of TCCE: $50.80 \pm 3.02 \mathrm{mg} / 100 \mathrm{~g}$ extract; total phenolic of TACE and TCCE are: 395.64 $\pm 38.93 \mathrm{mg} \mathrm{GE} / 100 \mathrm{~g}$ extract; $89.28 \pm 8.37 \mathrm{mg}$ $\mathrm{GE} / 100 \mathrm{~g}$ extract. Sonication's better performance than maceration was confirmed by the results of scanning electron miscroscope, in which more cell surface damage and deeper gaps were found. Sonication extraction method was an alternative extraction method to increase tamarillo extract rendemen and antioxidant potentials.

\section{BIBLIOGRAPHY}

Aadil, R. M., Zeng, X.-A., Abbasi, A. M., Khan, M. S., Khalid, S., Jabbar, S., \& Abid, M. (2014). Influence of power ultrasound on the quality parameters of grapefruit juice during storage. Sci Lett., 3, 1-8.

Altemimi, A., Watson, D. G., Choudhary, R., \& Dasari, M. R. (2016). Ultrasound Assisted Extraction of Phenolic Compounds from Peaches and Pumpkins. PLOS ONE, 17, $1-20$.

Annegowda, H. V, Bhat, R., \& Min-tze, L. (2012). Influence of sonication treatments and extraction solvents on the phenolics and antioxidants in star fruits. J. Food Sci Technol, 49(4), 510-514.

Asmara, Y., Bayu, A. K., Adi, S. G. ., Aini, F., \& Pudjihastuti, I. (2013). Rekayasa Proses Pembuatan Serbuk Pewarna Batik Biodegradable Berbahan Antosianin Limbah Kulit Terong Belanda (Chypomandra betaceae) dengan Kombinasi Ekstraksi Gelombang Ultrasonik dan Aqua Solvent. In SNST ke-4 2013, Semarang, Indonesia.

Atiqah, N. A. A. K., Maisarah, A. M., \& Asah, R. (2014). Comparison of antioxidant properties of tamarillo (Cyphomandra betacea), cherry tomato ( Solanumly copersicum var . cerasiform) and tomato (Lyopersicon esulentum). Intern Food Res J, 21(6), 2355-2362.

Benzie, I. F. F., \& Strain, J. J. (1996). The Ferric Reducing Ability of Plasma ( FRAP) as a Measure of " Antioxidant Power "': The FRAP Assay. J. Antiox.Anal. Biochem, 239, 70-76.

Celli, G. B., Ghanem, A., \& Brooks, M. S. (2015). Optimization of ultrasound-assisted extraction of anthocyanins from haskap berries ( Lonicera caerulea $\mathrm{L}$.) using Response Surface Methodology. J. Ultsonc, 27, 449-455.

Chemat, S., Aissa, A., Boumechhour, A., Arous, O., \& Ait-amar, $H$. (2016). Extraction mechanism of ultrasound assisted extraction and its effect on higher yielding and purity of artemisinin crystals from Artemesia annua L. leaves. J.Ultsonch, 1-20.

De Rosso, V. V., \& Mercadante, A. Z. (2007). HPLC - PDA - MS / MS of Anthocyanins and Carotenoids from Dovyalis and Tamarillo Fruits AND. J. Agric. Food Chem, 55, 91359141.

Eh, A. L. S., \& Teoh, S. (2012). Ultrasonics Sonochemistry Novel modified ultrasonication technique for the extraction of lycopene from tomatoes. J.Ultsonch, 19(1), 151-159. Giusti, M. M., \& Wrolstad, R. E. (2001). Characterization and Measurement of Anthocyanins by UV $\square$ Visible Spectroscopy. Current Protocols in Food Anal Chem, F1.2.1-F1.2.13

Ivanovic, J., Tadic, V., Dimitrijevic, S., Stamenic, M., Petrovic, S., \& Zizovic, I. (2014). Antioxidant properties of the anthocyanin-containing ultrasonic extract from blackberry cultivar "Čačanska Bestrna." Industrial Crops and Prod, 53, 274-281.

Jabbar, S., Abid, M., Hu, B., Wu, T., Muhammad, M., Lei, S., ... Zeng, X. (2014). Quality of carrot juice as in fl uenced by blanching and sonication treatments. LWT - Food SCi Technol, 55(1), 16-21.

Kurniawan, M., Izzati, M., Nurchayati, Y., Biologi, L., Tumbuhan, F., Biologi, J., ... Universitas, K. (2010). Kandungan Klorofil , Karotenoid, dan Vitamin C pada Beberapa Spesies Tumbuhan Akuatik. Buletin Anatom Fisiol, XVIII(1), 28-40.

Lianfu, Z., \& Zelong, L. (2008). Optimization and comparison of ultrasound / microwave assisted extraction ( UMAE ) and ultrasonic assisted extraction ( UAE ) of lycopene from tomatoes. J.Ultsonch, 15, 731-737.

Liang, N., \& Kitts, D. D. (2014). Antioxidant property of coffee components: Assessment of methods that define mechanism of action. Molecules, 19(11), 19180-19208.

Ma, Y., Chen, J., Liu, D., \& Ye, X. (2009). Simultaneous extraction of phenolic compounds of citrus peel extracts : Effect of ultrasound. J. Ultsonc, 16, 57-62.

Mandal, P., \& Ghosal, M. (2012). Antioxidant Activities of Different Parts of Tree Tomato Fruit. Inter J Pharm Sci Rev Res, 13(2), 39-47. 
Medina-torres, N., Ayora-talavera, T., Espinosa-andrews, $\mathrm{H}_{\text {., }}$ Sanchez-Contreras, A., \& Pacheco, N. (2017). Ultrasound Assisted Extraction for the Recovery of Phenolic Compounds from Vegetable Sources. Agronomy, 7(47), 1-19.

Molyneux, P. (2004). The use of the stable free radical diphenylpicryl- hydrazyl ( DPPH ) for estimating antioxidant activity. Songklanakarin J. Sci.Technol, 26(2), 212-219.

Namitha, K. K., \& Negi, P. S. (2010). Chemistry and biotechnology of carotenoids. Critical Rev Food Sci Nutr, 50(8), 1040-8398.

Osorio, C., Hurtado, N., Dawid, C., Hofmann, T., Heredia-mira, F. J., \& Lucía, A. (2012). Chemical characterisation of anthocyanins in tamarillo ( Solanum betaceum Cav .) and Andes berry ( Rubus glaucus Benth .) fruits. Food Chem, 132(4), 1915-1921.

Phan, A. D. T., Netzel, G., Wang, D., Flanagan, B. M., D’Arcy, B. R., \& Gidley, M. J. (2015). Binding of dietary polyphenols to cellulose : Structural and nutritional aspects. Food Chem, 171, 388-396.

Ramli, N. S., Ismail, P., \& Rahmat, A. (2014). Influence of Conventional and Ultrasonic-Assisted Extraction on Phenolic Contents, Betacyanin Contents, and Antioxidant Capacity of Red Dragon Fruit ( Hylocereus polyrhizus ). Scient Word J, 1-7.

Rocha, J. de C. G., Procopio, F. R., Mendonca, A. C., Vieira, L. M., Perrone, Í. T., Barros, F. A. R. de, \& Stringheta, P. C. (2017). Optimization of ultrasound-assisted extraction of phenolic compounds from jussara (Euterpe edulis M.) and blueberry (Vaccinium myrtillus) fruits. Food Sci Technol, 38(1), 45-53.

Rombaut, N., Tixer, A.-S., Bily, A., \& Chemat, F. (2014). Green extraction processes of natural products as tools for biorefinery. Biofuels Bioprod Bioref, 1-15.

Saikia, S., Mahnot, N. K., \& Mahanta, C. L. (2015). A comparative study on the effect of conventional thermal pasteurisation , microwave and ultrasound treatments on the antioxidant activity of five fruit juices. Food Sci Technol Inter, 22(4), 288-301.

Sancho, R. A. S., \& Pastore, G. M. (2012). Evaluation of the effects of anthocyanins in type 2 diabetes. Food Res Inter, 46(1), 378-386.

Santos, L. E. O., Zarate, L. X. P., \& Salcedo, L. O. G. (2015). Optimization of ultrasonic-assisted extraction of total carotenoids from peach palm fruit (Bactris gasipaes) by-products with sunflower oil using response surface methodology. J. Ultsonc, 1-8.

Sugiura, M., Nakamura, M., Ogawa, K., Ikoma, Y., \& Yano, M. (2015). High-serum carotenoids associated with lower risk for developing type 2 diabetes among Japanese subjects: Mikkabi cohort study. Diabetes Res Care, 13-20.

Žlabur, J. Š., Voća, S., Dobričević, N., Pliestić, S., Galić, A., \& Boričević, A. (2016). Ultrasound-assisted extraction of bioactive compounds from lemon balm and peppermint leaves. Int. Agrophys, 30, 95-104. 